\title{
The effect of sampling frequency on the accuracy of estimates of milk-fat yields of dairy cows
}

\author{
H. de Waal ${ }^{1+}$ and H.J. Heydenrych ${ }^{2}$ \\ ${ }^{1}$ ARC-Animal Improvement Institute, Private Bag X5013, Stellenbosch 7599, South Africa; ${ }^{2}$ Department of Animal \\ Science, University of Stellenbosch, Stellenbosch, 7599, South Africa
}

\begin{abstract}
Estimation of 300-day lactation yields of milk, fat, protein and lactose from combined morning and afternoon milk samples collected at five-weekly intervals is time-consuming, and proportional bulking of morning and evening samples is not always done correctly by farmers. This study was conducted to determine whether samples could be collected once daily without compromising the accuracy of yield estimates. The results of this study support the fiveweekly sampling procedure currently used by the South African National Dairy Cattle Performance Testing Scheme. However, replacement of proportional bulking of individual morning and evening samples with a single evening milk sample would not compromise accuracy provided that the relevant corrections are made to prevent over-estimation of milk-fat yields.
\end{abstract}

Key words: milk, dairy, cow, lactation

\#Author to whom correspondence should be addressed; E-mail: hendrik@infruit.agric.za

\section{Introduction}

In South Africa the estimation of breeding values of dairy bulls and cows is based on data derived from milk yields and samples collected by farmers during morning and evening milkings at five-week intervals. Milk samples collected during morning and evening milkings are combined and analyzed for fat, protein and lactose content at a central laboratory (Grobler \& Loubser, 1983). According to Dickinson \& McDonald (1970), all sampling methods are subject to bias and random variation. Although a certain degree of accuracy is sacrificed by interval sampling compared to continuous daily milk recording, the practical and financial feasibility of data recording regimes must be taken into account. There are, nonetheless, significant differences in the accuracy of lactation milk yield estimates between different sampling methods and sampling intervals (Anderson et al., 1989).

Milk-fat yield varies more than other milk components on a day-to-day basis and between morning and evening milkings. Gilbert et al. (1973) found that milk-fat yield differs between morning and evening milking even when the milking interval is precisely 12 hours. Erb et al. (1952) found that the milk yield of Jersey cows was 7.6\% higher during the morning milking than during the evening milking. Milk-fat yield, however, was $9.6 \%$ lower during the morning milking in comparison with the evening milking. Gilbert et al. (1973) found that the milk-fat percentage of Holstein-Friesland cows was $0.017 \pm 0.004$ percentage points higher during the evening milking than during the morning milking. The average milk-fat yield was $0.32 \pm 0.02 \mathrm{~kg}$ higher in the evening than in the morning. Correction factors are therefore necessary when estimates of milk-fat yields are based on single daily samples. This is particularly important in circumstances where day and night intervals differ appreciably (Hargrove \& Gilbert, 1984).

Milk recording is a time consuming process and proportionate bulking of morning and evening milk samples is often done incorrectly. There is a need to simplify the milk recording process by recording milk yields and collecting milk samples either during the morning or evening milking. This study was conducted determine whether samples could be collected once daily without compromising accuracy of the estimates derived from such data.

\section{Materials and Methods}

The study was conducted using two Holstein-Friesland herds (66 cows in herd 1 and 63 cows in herd 2) and two Jersey herds (56 cows in herd 3 and 46 cows in herd 4). Records and samples were collected at weekly intervals. Milk yields were recorded during the morning and evening milkings and separate milk samples were collected from all cows during the morning and evening milkings. A second set of milk samples was collected simultaneously and combined to form a composite sample. For both Holstein-Friesland herds there was a $12 \mathrm{~h}$ interval between morning and evening milkings. For both Jersey herds there was an $11 \mathrm{~h}$ interval between morning and evening milkings and a $13 \mathrm{~h}$ interval between the evening milking and the following morning milking. Comparisons were made between 
estimates of total lactation fat yield derived from weekly samples $v s$. samples taken every two, three, four, five or six weeks, and also from from combined evening and morning samples $v s$. single evening or single morning samples.

Intraclass correlations were calculated to determine the correspondence between the different procedures.

Total lactation yields estimated from the weekly milk recording and milk sampling procedure using composite morning and evening samples were used as reference values. Regression analyses were used to test the best estimate of lactation yield by regressing the estimates derived from different test intervals and sampling procedures on the weekly milk recording and milk sampling procedure.

\section{Results and Discussion}

It is evident from Table 1 that the accuracy of estimation of LFY improves as sampling frequency increases.

Table 1 Intraclass correlations between repeated measures of combined 24-hour milk-fat yield with different test intervals

\begin{tabular}{cccccccc}
\hline $\begin{array}{c}\text { Sampling } \\
\text { protocol }\end{array}$ & Herd & \multicolumn{7}{c}{ Number of weeks between tests } \\
& & 1 & 2 & 3 & 4 & 5 & 6 \\
\hline Combined & 1 & 0.46 & 0.40 & 0.37 & 0.39 & 0.28 & 0.32 \\
24-hour & 2 & 0.35 & 0.34 & 0.34 & 0.30 & 0.28 & 0.25 \\
& 3 & 0.47 & 0.41 & 0.37 & 0.37 & 0.37 & 0.34 \\
& 4 & 0.17 & 0.14 & 0.09 & 0.11 & 0.06 & 0.01 \\
\hline Single & 1 & 0.42 & 0.37 & 0.35 & 0.39 & 0.24 & 0.31 \\
Evening & 2 & 0.37 & 0.36 & 0.34 & 0.33 & 0.32 & 0.29 \\
& 3 & 0.44 & 0.37 & 0.32 & 0.32 & 0.30 & 0.31 \\
& 4 & 0.15 & 0.12 & 0.06 & 0.06 & 0.02 & 0.04 \\
\hline Single & 1 & 0.42 & 0.37 & 0.33 & 0.34 & 0.29 & 0.29 \\
morning & 2 & 0.32 & 0.30 & 0.31 & 0.26 & 0.24 & 0.21 \\
& 3 & 0.46 & 0.41 & 0.40 & 0.39 & 0.37 & 0.33 \\
& 4 & 0.19 & 0.19 & 0.15 & 0.20 & 0.12 & 0.12 \\
\hline
\end{tabular}

Table 2 Equations for the regression of lactation fat yield (LFY) estimated from composite (morning and evening) weekly samples $v s$. composite (morning and evening) samples collected at intervals of two, three, four or five weeks. Values in parentheses denote standard errors.

\begin{tabular}{cccc}
\hline Test interval (weeks) & Intercept $(\mathrm{kg})$ & Slope & $\mathrm{R}^{2}$ \\
\hline 2 & $-1.49( \pm 1.11)$ & $0.99( \pm 0.005)$ & 0.994 \\
3 & $-5.91 \pm \pm 1.78)$ & $1.018( \pm 0.008)$ & 0.985 \\
4 & $-3.33( \pm 2.05)$ & $1.001( \pm 0.009)$ & 0.980 \\
5 & $2.38( \pm 2.42)$ & $0.964( \pm 0.011)$ & 0.972 \\
6 & $-8.79( \pm 2.84)$ & $1.034( \pm 0.013)$ & 0.965 \\
\hline
\end{tabular}

The effect of test interval is shown in Table 2. The intercept on the y axis differed $(\mathrm{P}<0.01)$ from zero for the three- and six-weekly test intervals, while the slope differed $(\mathrm{P}<0.05)$ for only the six weekly test interval. No corrections are therefore needed if five-weekly milk samples are used. These results support the current practice of the National Dairy Cattle Performance Testing Scheme in which five-weekly combined milk samples are used to estimate LFY. The comparison between estimates derived from weekly combined milk samples and single evening milk samples is shown in Table 3. 
Table 3 Equations for regressions of estimates of lactation fat yield based on weekly combined milk samples $v s$. single evening samples for different test intervals. Values in parentheses denote standard errors.

\begin{tabular}{llll}
\hline Test interval (weeks) & Intercept $(\mathrm{kg})$ & Slope & $\mathrm{R}^{2}$ \\
\hline 1 & $18.32( \pm 3.11)$ & $0.948( \pm 0.014)$ & 0.950 \\
2 & $17.35( \pm 3.28)$ & $0.944( \pm 0.015)$ & 0.945 \\
3 & $14.62( \pm 3.55)$ & $0.958( \pm 0.016)$ & 0.937 \\
4 & $14.23( \pm 3.83)$ & $0.952( \pm 0.018)$ & 0.927 \\
5 & $21.59( \pm 4.55)$ & $0.927( \pm 0.021)$ & 0.895 \\
6 & $10.71( \pm 4.47)$ & $0.978( \pm 0.021)$ & 0.908 \\
\hline
\end{tabular}

All intercepts differed from zero $(\mathrm{P}<0.05)$ and the slopes of estimates of LFY derived from single evening milk samples taken every one, two and five-weeks differed $(\mathrm{P}<0.05)$ from unity (Table 3$)$. This indicates that appropriate test-interval corrections should be applied if LFY is estimated from evening milk sampling data. A comparison of estimates of LFY based on weekly combined milk sampling vs. single morning milk sampling is shown in Table 4. All intercepts were negative and differed from zero $(\mathrm{P}<0.01)$ and all slopes deviated $(\mathrm{P}<0.01)$ from unity. Lactation fat yields based on single morning milk sampling data will result in an under-estimation of LPY compared to estimates derived from combined weekly milk sampling. Corrections would therefore be necessary for all test intervals.

Table 4 Equations for regressions of estimates of lactation fat yield from weekly combined milk samples $v s$. single morning samples for different test intervals. Values in parentheses denote standard errors.

\begin{tabular}{cccc}
\hline Test interval (weeks) & Intercept $(\mathrm{kg})$ & Slope & $\mathrm{R}^{2}$ \\
\hline 1 & $-17.50( \pm 2.69)$ & $0.055( \pm 0.012)$ & 0.969 \\
2 & $-19.48( \pm 3.03)$ & $1.052( \pm 0.014)$ & 0.961 \\
3 & $-24.18( \pm 3.46)$ & $1.048( \pm 0.016)$ & 0.937 \\
4 & $-20.78( \pm 3.83)$ & $1.056( \pm 0.017)$ & 0.946 \\
5 & $-19.67( \pm 3.99)$ & $1.061( \pm 0.018)$ & 0.936 \\
6 & $-27.17( \pm 4.35)$ & $1.090( \pm 0.020)$ & 0928 \\
\hline
\end{tabular}

\section{Conclusions}

This study showed that milk records taken at five-week intervals would not result in a less accurate estimate of lactation fat yield than daily milk records. For practical reasons, a single milk sample taken at the evening milking is strongly recommended provided that the relevant corrections are applied to the data to prevent over-estimation of milk-fat yield.

\section{References}

Anderson, S.M., Mao, I.L. \& Gill, J.L., 1989. Effect of frequency and precision of estimating total lactation milk yield and characteristics of the lactation curve. J. Dairy Sci. 72, 2387.

Dickinson, F.N. \& McDaniel, B.T., 1970. Single-milking yields versus 24-hour yields for estimating lactation milk production by the test interval method. J. Dairy Sci. 53, 200.

Erb, R.E., Goodwin, M.M., Morrison, R.A. \& Shaw, A.O., 1952. Lactation studies. III. Variations in daily yields of dairy cows. J. Dairy Sci. 35, 967.

Gilbert, G.R., Hargrove, L.H. \& Kroger, M., 1973. Diurnal variations in milk yield, fat yield, milk-fat percentage, and milk protein percentage of Holstein-Friesian cows. J. Dairy Sci. 56, 409.

Grobler, B.R. \& Loubser, L.F.B., 1983. Die ontwikkeling van melkprestasietoetsing in die RSA. Nasionale Melkdierprestasie- en Nageslagtoetsskema. Jaarverslag 1983, vol. 3.

Hargrove, G.L. \& Gilbert, G.R., 1984. Differences in morning and evening sample milkings and adjustment to daily weights and percents. J. Dairy Sci 67, 194.

Palmer, R.W., Jensen, E.L. \& Hardie, A.R., 1 994. Removal of within-cow differences between morning and evening milk yields. J. Dairy Sci. 77, 2663. 